\title{
How do existing HIV-specific instruments measure up? Evaluating the ability of instruments to describe disability experienced by adults living with HIV
}

Kelly K O'Brien ${ }^{1,2,3^{*}}$, Ahmed M Bayoumi ${ }^{1,2,4}$, Carol Strike ${ }^{5,6}$, Nancy L Young ${ }^{1,7}$, Kenneth King ${ }^{8}$, Aileen M Davis ${ }^{1,9}$

\begin{abstract}
Background: Despite the multitude of health challenges faced by adults living with HIV, we know of no HIVspecific instrument developed for the purpose of describing the health-related consequences of HIV, a concept known as disability. In a previous phase of research, adults living with HIV conceptualized disability as symptoms/ impairments, difficulties carrying out day-to-day activities, challenges to social inclusion, and uncertainty that may fluctuate on a daily basis and over the course of living with HIV. In this paper, we describe the extent to which existing HIV-specific health-status instruments capture the experience of disability for adults living with HIV.

Methods: We searched databases from 1980 to 2006 for English language, HIV-specific, self-reported questionnaires consisting of at least two items that were tested for reliability and validity. We then conducted a content analysis to assess how well existing questionnaires describe disability as defined by the Episodic Disability Framework, a framework that conceptualizes this experience from the perspective of adults living with HIV. We matched items of the instruments with categories of the framework to evaluate the extent to which the instruments capture major dimensions of disability in the framework.
\end{abstract}

Results: We reviewed 4274 abstracts, of which 30 instruments met the inclusion criteria and were retrieved. Of the four major dimensions of disability, symptoms/impairments were included in all 30 instruments, difficulties with day-to-day activities in 16, challenges to social inclusion in 16, and uncertainty in 9 . Seven instruments contained at least 1 item from all 4 dimensions of disability (breadth) however, the comprehensiveness with which the dimensions were represented (depth) varied among the instruments.

Conclusions: In general, symptoms/impairments and difficulties carrying out day-to-day activities were the disability dimensions characterized in greatest depth while uncertainty and challenges to social inclusion were less well represented. Although none of the instruments described the full breadth and depth of disability as conceptualized by the Episodic Disability Framework, they provide a foundation from which to build a measure of disability for adults living with HIV.

\section{Background}

With longer survival, HIV-positive individuals are facing an increasing variety of health-related consequences and symptoms related to HIV infection, associated treatment, and concurrent health conditions [1-11].

\footnotetext{
* Correspondence: kelly.obrien@utoronto.ca

${ }^{1}$ Department of Health Policy, Management and Evaluation, University of Toronto, Toronto, Ontario, Canada

Full list of author information is available at the end of the article
}

Together, these experiences may be conceptualized as disability. We developed a conceptual framework of disability from the perspective of adults living with HIV. In the Episodic Disability Framework, adults living with HIV defined disability as symptoms/impairments, difficulties carrying out day-to-day activities, challenges to social inclusion, and uncertainty that may fluctuate on a daily basis and over the entire course living with HIV $[12,13]$. 
Developing programs or interventions to address HIVrelated disability mandates the development of a measurement instrument. A patient-reported disability questionnaire might assess the impact of disability for both clinical care and societal level decision making. To date, we know of no instrument developed for the purpose of describing HIV-specific disability. Related instruments, such as functional status and quality of life measures, capture some aspects of disability but may not be comprehensive when considering the range of health-related consequences of HIV [14-19]. Generic disability instruments may not capture population-specific disability experiences [20-23]. The purpose of this research was to evaluate the extent to which HIV-specific health status instruments capture disability experienced by adults living with HIV using the Episodic Disability Framework.

\section{Methods}

\section{The Episodic Disability Framework}

In a prior phase of research, we developed a conceptual framework of disability from the perspective of adults living with HIV. Specifically, we conducted four focus groups and 15 face-to-face interviews with 38 adults living with HIV, asking individuals to describe their health-related challenges, the physical, social and psychological areas of their life affected, and the impact of these challenges on their overall health. The resulting Episodic Disability Framework conceptualizes disability as multi-dimensional and episodic in nature. The framework is comprised of three main components: 1) dimensions of disability, 2) contextual factors that may exacerbate or alleviate disability, and 3) triggers or life events that may initiate a major or momentous episode for adults living with HIV. Details of this framework were previously published $[12,13]$.

\section{Instruments: Search Strategy and Inclusion Criteria}

To identify measures related to disability, we systematically searched the health and psychology literature for instruments that capture elements of the disability experience for adults living with HIV (Figure 1). We searched the following databases for articles published between 1980 and March 2006: MEDLINE, CINAHL, HAPI, EMBASE, and PsycINFO. Subject headings included exploded terms for HIV, HIV infections, health status indicators, quality of life, disability evaluation, behaviour and behaviour mechanisms, activities of daily living, psychiatric status rating scales, data collection, work, socioeconomic factors, signs and symptoms, mental disorders, uncertainty, culture, family, social environment, social isolation, socialization, sociometric techniques, religion, spiritual therapies, and stigma. Slight modifications of this strategy were made for each database. We reviewed abstracts yielded from the search for instruments relevant to disability. If it was unclear from the abstract whether an instrument was applicable, we pulled the full article for review. We also searched reference lists from pertinent articles for potentially relevant instruments.

We included instruments that were published in English, were HIV-specific self-reported questionnaires including at least two items, and had been tested for reliability and validity. We excluded instruments that measured constructs un-related to the four dimensions of disability in the Episodic Disability Framework. When we were uncertain whether to include an instrument or if the instrument was not published within the article, we requested further information from study authors.

\section{Analysis}

We analyzed instruments using content analysis, a qualitative method in which pre-defined categories of text are matched against each other and used to compare documents [24]. We compared each instrument against the Episodic Disability Framework [12] We evaluated the instruments against the dimensions of disability in the framework [12] (Figure 2). These dimensions were classified into 10 high-level categories and 72 detailed subcategories. For example, an item about fatigue received a high-level category of "symptom/impairment" and a sub-category of "fatigue/decreased energy level." We created new sub-categories for instrument items that did not match a pre-identified classification. These new subcategories represented contextual factors or triggers of disability or items beyond the scope of the framework. See Additional File 1 for a detailed overview of categories.

One author categorized all instruments. To assess validity, we assessed agreement between this categorization and that of a community-based author who categorized eight randomly selected instruments. We calculated percent agreement for each instrument by dividing the number of items categorized identically by the total number of items in the instrument. We determined percent agreement for detailed sub-categories, high-level categories, and dimensions of disability. The two raters reconciled any differences by consensus.

We mapped items from the instruments onto a matrix according to the category that they represented within the disability framework. An instrument with greater representation of the dimensions of disability in this matrix was determined a priori to possess a greater ability to describe the construct of disability for adults living with HIV. We classified an instrument as having breadth if it contained at least one item from each of the four disability dimensions. We classified an instrument as having depth (for each dimension) if it contained items which corresponded to all pre-specified categories in a given dimension. 


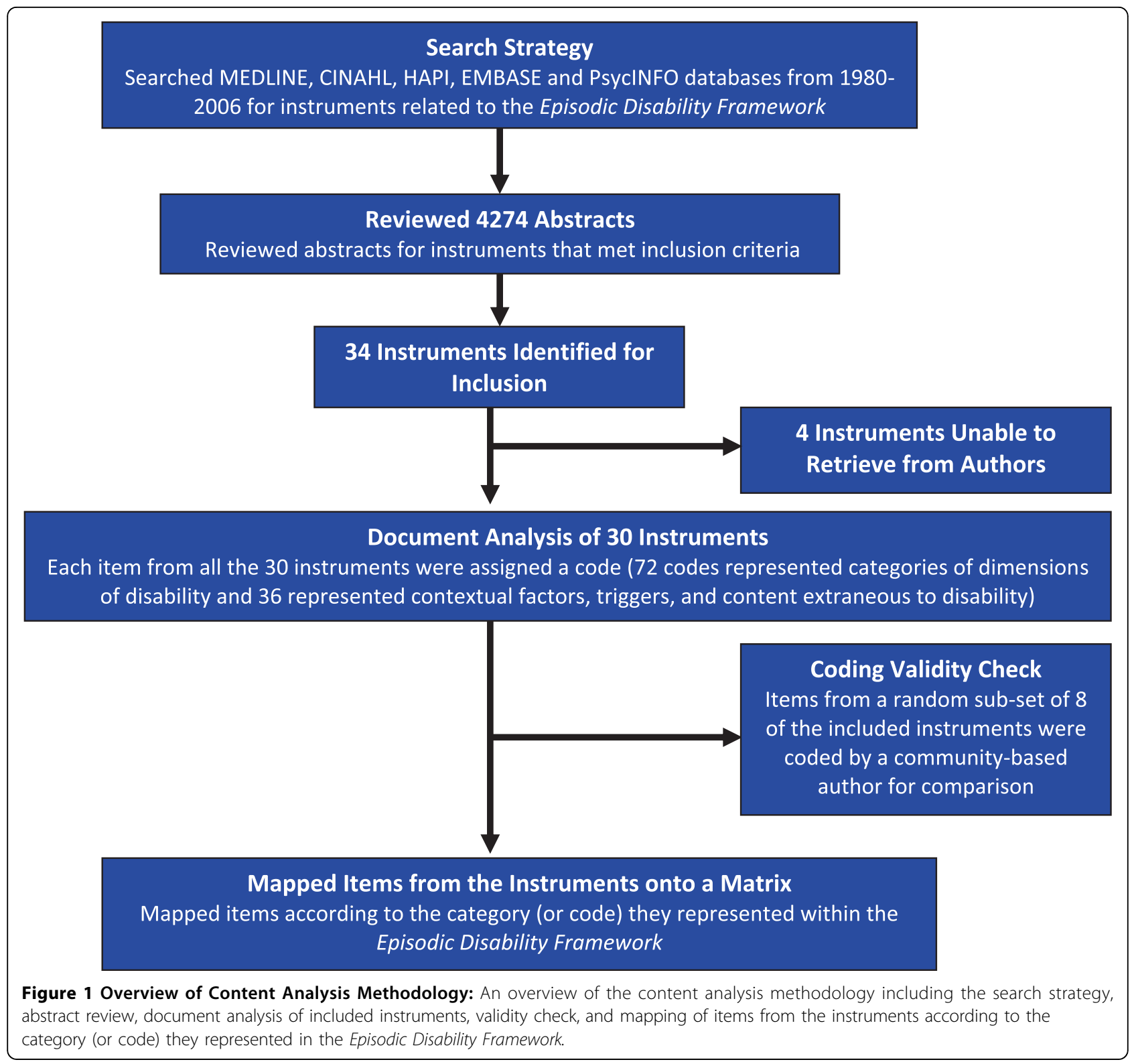

\section{Results}

We reviewed 4274 abstracts, of which 34 instruments met the inclusion criteria. Instruments were excluded because they were un-related to the Episodic Disability Framework, were measures of adherence to medications, attitudes towards death, internal locus of control, attitudes towards health providers, quality of care, satisfaction, utility indices, disclosure, knowledge about HIV/ AIDS, sexual and risk behaviour. Of the 34 instruments identified for inclusion, 30 were retrieved (Table 1). We were unable to retrieve four instruments after three attempts to contact the authors [25-28].

\section{Description of Instruments}

The included instruments were developed between 1989 and 2006, 19 of which were published after 1996 when triple drug combination antiretroviral therapy started to be used widely. The number of items in the instruments ranged from nine in the Impact of Weight Loss Scale to 177 in the HIV Overview of Problems-Evaluation System (HOPES). Instruments measured nine different constructs as identified by authors, the majority of which included health-related quality of life/quality of life (HRQL/QOL) ( $\mathrm{n}=14$ instruments), followed by symptoms $(n=7)$, body image $(n=2)$, stress $(n=2)$, fatigue 


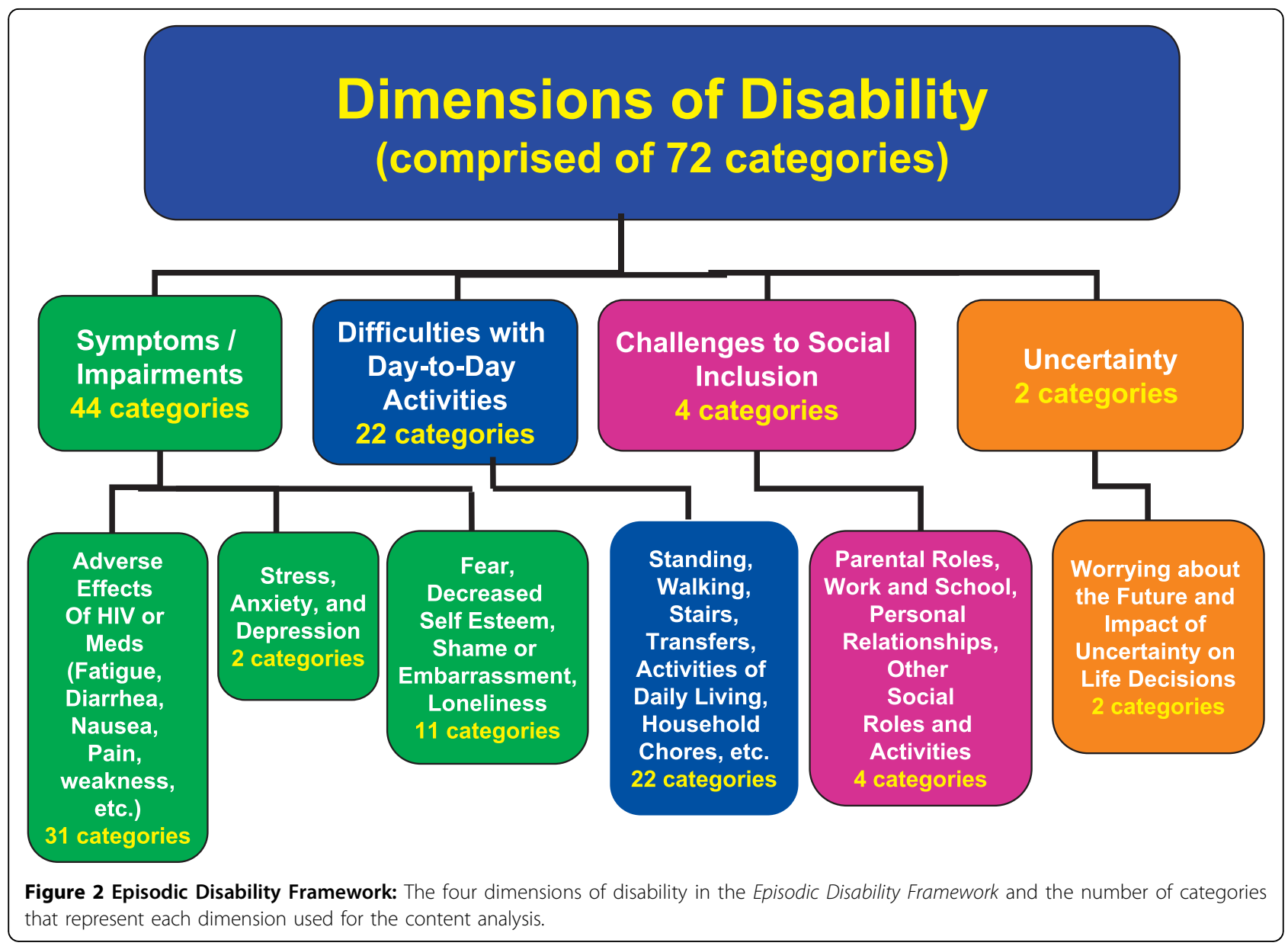

$(\mathrm{n}=1)$, diarrhea $(\mathrm{n}=1)$, loneliness $(\mathrm{n}=1)$, psychological adjustment $(\mathrm{n}=1)$, and impact of weight loss $(\mathrm{n}=1)$ (Table 1).

\section{Document Analysis}

There were 108 possible categories to which an item could be assigned for the document analysis, 72 of which represented categories within the four dimensions of disability within the Episodic Disability Framework (Figure 2). An additional 36 categories were generated; 15 of which represented contextual factors $(n=12)$ and triggers $(\mathrm{n}=3)$ of disability within the framework and 21 that went beyond the scope of the Episodic Disability Framework (see Additional File 1 for a detailed overview of categories).

Our validity check demonstrated that agreement for the sub-set of eight instruments varied depending on the level to which the items were categorized. At the most detailed category level (108 possible categories), agreement ranged from $52 \%$ in the HIV Quality of Life Questionnaire (HIV-QL31) to 79\% in the Functional Assessment of HIV Infection (FAHI) Questionnaire. At the high-level categorization (10 possible categories), agreement ranged from $61 \%$ in the HIV-QL31 to $85 \%$ in the FAHI Questionnaire. At the dimension of disability level (4 possible categories), we achieved $100 \%$ agreement for all eight instruments.

\section{Breadth and Depth of Disability in Instruments}

Of the four major dimensions in the Episodic Disability Framework, symptoms/impairments were included in all 30 instruments, difficulties with day-to-day activities in 16 , challenges to social inclusion in 16 , and uncertainty in 9 (Table 2). Seven instruments demonstrated breadth, that is, they measured some part of all 4 dimensions of disability [29-35]. The number of items in these instruments ranged from 29 (HIV/AIDS Stress Scale) to 177 (HOPES). Authors classified six of the seven scales as HRQL/QOL instruments [29-34], and the other, a stress scale [35] (Table 1).

No instrument captured all of the dimensions of disability comprehensively. The depth in which the dimensions of disability were represented varied among the instruments (Table 2). We highlight eight instruments that most comprehensively represented each of the 4 dimensions of disability. 
Table 1 Characteristics of Instruments Included in the Content Analysis ( $\mathbf{n}=\mathbf{3 0}$ instruments)

\begin{tabular}{|c|c|c|c|c|}
\hline Instrument & Authors & $\begin{array}{l}\text { Construct } \\
\text { Measured^ }\end{array}$ & $\begin{array}{l}\text { Year } \\
\text { Developed }\end{array}$ & $\begin{array}{l}\text { Number of } \\
\text { Items }\end{array}$ \\
\hline Body Image Scale [41] & Martinez et al & Body Image & 2005 & 12 \\
\hline $\begin{array}{l}\text { Assessment of Body Change and Diarrhea Scale } \\
\text { (ACBD) [42] }\end{array}$ & Guaraldi et al & Body Image & 2006 & 27 \\
\hline HIV Diarrhea Questionnaire [43] & Mertz et al & Diarrhea & 1995 & 14 \\
\hline HIV-Related Fatigue Scale [44] & Barroso \& Lynn & Fatigue & 2000 & 56 \\
\hline Health-Related Quality of Life Scale (HIV-QOL) [18] & Cleary et al & $\mathrm{HRQL/QOL}$ & 1993 & 46 \\
\hline $\begin{array}{l}\text { AIDS Health Assessment Questionnaire } \\
\text { (AIDS-HAQ) [45] }\end{array}$ & Lubeck \& Fries & $\mathrm{HRQL/QOL}$ & 1994 & 55 \\
\hline Functional Assessment of HIV Infection (FAHI) $[29,46]$ & Cella \& Peterman & HRQL/QOL & 1997 & 47 \\
\hline $\begin{array}{l}\text { HIV Overview of Problems-Evaluation System } \\
\text { (HOPES) }[30,47]\end{array}$ & Ganz \& Schag & $\mathrm{HRQL/QOL}$ & 1992 & 177 \\
\hline HIV/AIDS Targeted QOL (HAT-QOL) $[31,48]$ & Holmes \& Shea & $\mathrm{HRQL/QOL}$ & 1999 & 35 \\
\hline $\begin{array}{l}\text { HIV Patient Assessed Report of Status and Experience } \\
\text { (HIV-PARSE) [49] }\end{array}$ & Bozzette et al & HRQL/QOL & 1989 & 144 \\
\hline HIV QOL Questionnaire (HIV-QL31) [32] & Leplege et al & HRQL/QOL & 1997 & 31 \\
\hline $\begin{array}{l}\text { Medical Outcomes Survey HIV Health Survey (MOS- } \\
\text { HIV) [50,51] }\end{array}$ & Wu et al & $\mathrm{HRQL/QOL}$ & 1997 & 35 \\
\hline $\begin{array}{l}\text { Multidimensional QOL Questionnaire for HIV/AIDS } \\
\text { (MQOL-HIV) [33] }\end{array}$ & Avis et al & $\mathrm{HRQL/QOL}$ & 1994 & 40 \\
\hline $\begin{array}{l}\text { World Health Organization QOL HIV Instrument } \\
\text { (WHOQOL-HIV) }[34,52,53]\end{array}$ & $\begin{array}{l}\text { Fang, O'Connell \& WHO HIV/AIDS Quality } \\
\text { of Life Group }\end{array}$ & $\mathrm{HRQL/QOL}$ & 2002 & 120 \\
\hline General Health Self Assessment [54] & Lenderking et al & $\mathrm{HRQL/QOL}$ & 1997 & 50 \\
\hline Living with HIV Scale[55] & Holzemer et al & HRQL/QOL & 1998 & 32 \\
\hline HIV Cost and Services Utilization Tool [56] & Hays et al & $\mathrm{HRQL/QOL}$ & 1998 & 31 \\
\hline AIDS Clinical Trials Group (ACTG Outcomes SF-21) [57] & $\begin{array}{l}\text { AIDS Clinical Trials Group Outcomes } \\
\text { Committee }\end{array}$ & HRQL/QOL & 1999 & 21 \\
\hline Existential Loneliness Questionnaire [58] & Mayers et al & Loneliness & 2002 & 22 \\
\hline Mental Adjustment to HIV Scale (MAHIVS) [59] & Ross et al & $\begin{array}{l}\text { Psychological } \\
\text { Adjustment }\end{array}$ & 1994 & 40 \\
\hline HIV/AIDS Stress Scale [35] & Pakenham \& Rinaldis & Stress & 2002 & 29 \\
\hline HIV Stressor Scale [60] & Thompson et al & Stress & 1996 & 25 \\
\hline Physical Symptoms of Illness Scale [27] & Nokes et al & Symptoms & 1994 & 15 \\
\hline HIV Symptom Index (Justice) [61] & Justice et al & Symptoms & 1998 & 20 \\
\hline Sign and Symptom Checklist for HIV (SSC-HIV) [62] & Holzemer et al & Symptoms & 1999 & 26 \\
\hline Riverside Symptom Checklist [63] & Burgess et al & Symptoms & 1993 & 28 \\
\hline $\begin{array}{l}\text { Revised Sign and Symptom Checklist for HIV } \\
\text { (SSC-HIVrev) [64] }\end{array}$ & Holzemer et al & Symptoms & 2001 & 72 \\
\hline HIV Symptom Index (Whalen) [65] & Whalen & Symptoms & 1994 & 12 \\
\hline Self-Report Slowness Scale (SRSS) [66] & Lopez et al & Symptoms & 1998 & 11 \\
\hline Impact of Weight Loss Scale [67] & Wagner \& Rabkin & Weight Loss & 1999 & 9 \\
\hline
\end{tabular}

$\wedge$ Construct measured as defined by the author.

$\mathrm{HRQL}=$ health-related quality of life; $\mathrm{QOL}=$ quality of life

The HOPES instrument most broadly captured symptoms/impairments representing 25 categories, eight of which related to stress, anxiety and depression and emotional challenges. The Revised Sign and Symptom Checklist (SSC-HIVrev) captured 27 categories, of which two addressed stress, anxiety and depression, and emotional challenges. Alternatively, the World Health
Organization's Quality of Life HIV Instrument (WHOQOL-HIV) and Living with HIV Scale were the most comprehensive at capturing symptoms/impairments that specifically related to stress, anxiety and depression, and emotional challenges with seven and eight categories, respectively, but possessed fewer categories that represented physical symptoms/impairments (4 categories in 
Table 2 Breadth and Depth of Disability in Instruments

\begin{tabular}{|c|c|c|c|c|c|c|}
\hline & Dimensions of Dis & lity & & & $\begin{array}{l}\text { Breadth ar } \\
\text { Depth of } \\
\text { Disability }\end{array}$ & \\
\hline Instrument & $\begin{array}{l}\text { Symptoms/ } \\
\text { Impairment } / 44 \\
\text { categories }\end{array}$ & $\begin{array}{l}\text { Difficulties with Day-to- } \\
\text { Day Activities/22 } \\
\text { categories }\end{array}$ & $\begin{array}{l}\text { Challenges to Social } \\
\text { Inclusion/4 categories }\end{array}$ & $\begin{array}{l}\text { Uncertainty/ } \\
2 \text { categories }\end{array}$ & $\begin{array}{l}\text { Breadth } \\
\text { (Yes/No) }\end{array}$ & $\begin{array}{c}\text { Depth } \\
\text { (Yes/ } \\
\text { No) }\end{array}$ \\
\hline Body Image Scale & 5 & & & & No & No \\
\hline $\begin{array}{c}\text { Assessment of Body Change and } \\
\text { Diarrhea Scale (ACBD) }\end{array}$ & 9 & & & 1 & No & No \\
\hline HIV Diarrhea Questionnaire & 2 & & & & No & No \\
\hline HIV-Related Fatigue Scale & 4 & 10 & 2 & & No & No \\
\hline $\begin{array}{l}\text { Health-Related Quality of Life } \\
\text { Scale (HIV-QOL) }\end{array}$ & 18 & 8 & & & No & No \\
\hline $\begin{array}{l}\text { AIDS Health Assessment } \\
\text { Questionnaire (AIDS-HAQ) }\end{array}$ & 2 & 12 & & & No & Yes \\
\hline $\begin{array}{l}\text { Functional Assessment of HIV } \\
\text { Infection (FAHI) }\end{array}$ & 12 & 1 & 4 & 1 & Yes & Yes \\
\hline $\begin{array}{l}\text { HIV Overview of Problems- } \\
\text { Evaluation System (HOPES) }\end{array}$ & 25 & 10 & 4 & 1 & Yes & Yes \\
\hline $\begin{array}{l}\text { HIV/AIDS Targeted QOL (HAT- } \\
\text { QOL) }\end{array}$ & 7 & 1 & 2 & 2 & Yes & Yes \\
\hline $\begin{array}{l}\text { HIV Patient Assessed Report of } \\
\text { Status and Experience (HIV- } \\
\text { PARSE) }\end{array}$ & 21 & 12 & 3 & & No & Yes \\
\hline $\begin{array}{l}\text { HIV QOL Questionnaire (HIV-QL- } \\
\text { 31) }\end{array}$ & 9 & 6 & 1 & 1 & Yes & No \\
\hline $\begin{array}{l}\text { Medical Outcomes Survey HIV } \\
\text { Health Survey (MOS-HIV) }\end{array}$ & 8 & 6 & 2 & & No & No \\
\hline $\begin{array}{c}\text { Multidimensional QOL } \\
\text { Questionnaire for HIV/AIDS } \\
\text { (MQoL-HIV) }\end{array}$ & 8 & 8 & 1 & 1 & Yes & No \\
\hline $\begin{array}{l}\text { World Health Organization QOL } \\
\text { HIV Instrument (WHOQOL-HIV) }\end{array}$ & 11 & 6 & 3 & 1 & Yes & Yes \\
\hline General Health Self Assessment & 16 & 7 & 2 & & No & No \\
\hline Living with HIV Scale & 9 & & & & No & Yes \\
\hline $\begin{array}{c}\text { HIV Cost and Services Utilization } \\
\text { Tool }\end{array}$ & 4 & 10 & 2 & & No & No \\
\hline $\begin{array}{l}\text { AIDS Clinical Trials Group (ACTG } \\
\text { Outcomes SF-31) }\end{array}$ & 5 & 6 & 2 & & No & No \\
\hline $\begin{array}{l}\text { Existential Loneliness } \\
\text { Questionnaire }\end{array}$ & 4 & & 1 & & No & No \\
\hline $\begin{array}{c}\text { Mental Adjustment to HIV Scale } \\
\text { (MAHIVS) }\end{array}$ & 4 & & & 1 & No & No \\
\hline HIV/AIDS Stress Scale & 8 & 5 & 3 & 1 & Yes & No \\
\hline HIV Stressor Scale & 1 & & 2 & & No & No \\
\hline $\begin{array}{l}\text { Physical Symptoms of Illness } \\
\text { Scale }\end{array}$ & 12 & & & & No & No \\
\hline HIV Symptom Index (Justice) & 18 & & & & No & No \\
\hline $\begin{array}{c}\text { Sign and Symptom Checklist for } \\
\text { HIV (SSC-HIV) }\end{array}$ & 13 & & & & No & No \\
\hline Riverside Symptom Checklist & 18 & & & & No & No \\
\hline $\begin{array}{l}\text { Revised Sign and Symptom } \\
\text { Checklist for HIV (SSC-HIVrev) }\end{array}$ & 27 & & & & No & Yes \\
\hline HIV Symptom Index (Whalen) & 12 & & & & No & No \\
\hline Self-Report Slowness Scale (SRSS) & 1 & 9 & & & No & No \\
\hline Impact of Weight Loss Scale & 3 & & 2 & & No & No \\
\hline
\end{tabular}

Number of categories of disability represented for each dimension within existing HIV-specific instruments (in alphabetical order based on construct measured). Breadth of disability is defined as an instrument having at least 1 item (or category) represented in each of the four disability dimensions. Depth of disability is defined as having all possible categories represented in a given dimension. 
the WHOQOL-HIV and 1 category in the Living with HIV Scale).

For difficulties with day-to-day activities, the AIDS Health Assessment Questionnaire (AIDS-HAQ) and HIV Patient Assessed Report of Status and Experience (HIV-PARSE) each captured the most depth in this dimension (Table 2). Items captured a range of daily activities, some of which included walking, stair negotiation, activities of daily living, and household chores, all of which were sub-categories in the Episodic Disability Framework.

The FAHI and the HOPES represented all categories of challenges to social inclusion. The most common element of social inclusion missing from the other instruments that represented this dimension related to items that captured the challenges related to fulfilling parental roles (Table 2).

Uncertainty was less well represented by the instruments. The HIV/AIDS Targeted Quality of Life Scale (HAT-QOL) was the most comprehensive capturing both categories from this dimension. The remaining eight instruments (out of nine) that represented the dimension of uncertainty all captured one category comprised of items that addressed worrying about the future, but did not address the impact uncertainty has on making life decisions (Table 2).

Five of the eight comprehensive instruments were developed from 1996 onwards (Table 1). These instruments frequently captured challenges to social inclusion and uncertainty. Four instruments (FAHI, HOPES, HATQOL and WHOQOL-HIV) demonstrated both breadth and depth. The HOPES was the only instrument that demonstrated depth in more than one dimension (symptoms/impairments and challenges to social inclusion).

\section{Discussion}

No existing HIV-specific health instrument fully captured both the breadth and depth of disability as conceptualized from the perspective of adults living with HIV in the Episodic Disability Framework. Several possible reasons explain this finding. First, these instruments were not developed to measure disability. Accordingly, we did not expect these instruments to fully capture the breadth and depth of disability. Second, disability is a new and emerging construct in the context of HIV. Recent development of the Episodic Disability Framework identified features of disability that were not considered a component of disablement in earlier generic disability frameworks, which explains why uncertainty was less represented among these older measures. Third, many instruments were developed prior to the advent of combination antiretroviral therapy and may not address associated new complexities relating to adverse effects, stigma and disclosure, access issues, and uncertainty about long term outcomes of treatment. Fourth, many of the quality of life instruments we studied were modified from existing generic instruments (e.g. MOS-HIV) or disease-specific instruments in other contexts such as cancer (e.g. HOPES). Such instruments might not capture disablement unique to adults living with HIV, such as issues related to returning to work. Fifth, a greater number of items did not always translate into a greater ability for an instrument to capture disability. For example, while two instruments appeared to possess breadth or depth at capturing dimensions of disability, they were lengthy comprised of more than 140 items (HIV-PARSE and HOPES scale). They demonstrated redundancy within a given category raising questions about feasibility for use of these measures in a clinical setting. Altogether, it is not surprising that existing instruments do not fully address the spectrum of disability for adults living with HIV. Nevertheless, analyses of these questionnaires may serve as a foundation from which to build a disability instrument.

A measure of disability that corresponds to dimensions of the Episodic Disability Framework could be developed by pooling items from existing instruments into a new one for adults living with HIV. For example, most items from existing instruments represented symptoms/impairments from the framework. This was not surprising given 16 of the 30 instruments were developed for the purpose of either measuring a combination of symptoms $(\mathrm{n}=7)$ or a specific symptom/impairment $(\mathrm{n}=9)$. Difficulties with day-to-day activities also were well captured by the instruments, commonly represented in instruments originally developed to measure symptoms/impairments and HRQL/QOL. The depth in which these two dimensions were represented provide a comprehensive group of existing items from which to pool together and formulate domains of symptoms/ impairments and difficulties with day-to-day activities of a future disability measure.

Challenges to social inclusion and uncertainty were less well represented in the instruments. Since the introduction of combination antiretroviral therapy, there has been a shift to consider the broader health-related consequences that adults living with HIV might experience and specifically disability is becoming increasingly important to consider in the context of HIV [36]. Issues related to labour force and income support and worrying about the unpredictable and episodic nature of HIV are examples of types of disability faced by adults living longer with HIV. Accordingly, newer instruments appeared to more closely capture these two disability dimensions in the Episodic Disability Framework and may be a source from which to draw existing items for a new measure. Nevertheless, generation of new items will likely be required to fully capture these dimensions. 
Results from this content analysis may be used to build a new HIV-specific disability questionnaire. For each of the disability dimensions we may identify instruments that most comprehensively cover a dimension with the least amount of item redundancy. Items from the next most comprehensive instruments may be used to fill any remaining gaps in existing categories. Categories not represented by any existing items would require item generation and could be done in consultation with adults living with HIV. This process may yield a collection of items that comprehensively represent each of the four disability dimensions that could be combined to comprise a new measure of HIV-disability. Once developed, measurement properties of this questionnaire including sensibility, validity, reliability and responsiveness could be assessed with adults living with HIV.

Our study has limitations. We excluded generic instruments or instruments developed for use with other illness populations in order to focus on describing disability specifically from the experience of adults living with HIV. We also excluded questionnaires that addressed other components of the Episodic Disability Framework (contextual factors and triggers of disability). However, these instruments may possess content that relates to the dimensions of disability experienced by adults living with HIV. We only cross-validated eight instruments in the document analysis from which low levels of agreement at the sub-category level were initially attained. This was likely due to the large number of categories that an item could be assigned. New questionnaires also have been published since March 2006 and are not captured in this analysis. We performed an updated search from 2006-July 2010 for new HIV-specific health status instruments. Results yielded four instruments that appeared to meet our inclusion criteria [37-40]. Three instruments were HRQL/QOL measures; the Missoula-Vitas Quality-of-Life Index developed to assess quality of life in advanced HIV illness in a palliative care setting [37], the Neurological Quality of Life Questionnaire, a general measure of quality of life in HIV infection [38], and the Chronic Illness Quality of Life Ladder developed to assess quality of life across four time periods (past, present, future, and life without a diagnosis of HIV) [39]. The fourth instrument was a lipodystrophy scale developed to assess the severity of lipodystrophy from the perspective of individuals living with HIV [40]. Similar to the instruments included in our study, none of these instruments were developed to assess the construct of disability. Also, none contained items that represent the dimension of uncertainty.

\section{Conclusions}

No existing HIV-specific instrument fully captures the breadth and depth of disability experienced by adults living with HIV as conceptualized by the Episodic Disability Framework. Symptoms/impairments and difficulties carrying out day-to-day activities were characterized in greatest depth among most instruments, whereas challenges to social inclusion and uncertainty were less well represented. Nevertheless, these instruments may serve as a foundation from which to build a future instrument of disability. Future steps include using the Episodic Disability Framework as a foundation from which to establish a collection of items that will formulate a new instrument to describe disability experienced by adults living with HIV. Development of a new HIV disability questionnaire is currently underway.

\section{Additional material}

Additional file 1: Detailed Overview of Categories and SubCategories (and Codes) for the Document Analysis of Existing HIVSpecific Instruments

\section{Acknowledgements}

This research was supported by the Wellesley Institute. We gratefully acknowledge the members of the Community Advisory Committee including Winston Husbands (AIDS Committee of Toronto), Ken King (Canadian Working Group on HIV and Rehabilitation), Claudia Medina (Toronto People with AIDS Foundation) and James Murray (AIDS Bureau, Ontario Ministry of Health and Long Term Care) for their contributions throughout this study. We thank Elizabeth Uleryk who assisted with the search strategy, Cindy Ellerton for requesting instruments from the authors, and all of the authors who corresponded and generously provided us with copies of the instruments.

Dr. Kelly O'Brien was supported by a Fellowship from the Canadian Institutes of Health Research (CIHR), HIV/AIDS Research Program. Dr. Ahmed Bayoumi was supported by a Career Scientist Award from the Ontario HIV Treatment Network. Salary and infrastructure support for Dr. Carol Strike were provided by the Ontario Ministry of Health and Long Term Care. Dr. Nancy Young is supported by a Canada Research Chair from the CIHR. The Centre for Research on Inner City Health is supported in part by a grant from the Ontario Ministry of Health and Long-Term Care. The views expressed in this article are those of the authors, and no official endorsement by supporting agencies is intended or should be inferred.

\section{Author details}

Department of Health Policy, Management and Evaluation, University of Toronto, Toronto, Ontario, Canada. ${ }^{2}$ Centre for Research on Inner City Health, The Keenan Research Centre in the Li Ka Shing Knowledge Institute, St. Michael's Hospital, 30 Bond Street, Toronto, Ontario, M5B 1W8, Canada. ${ }^{3}$ School of Rehabilitation Science, McMaster University, 1400 Main Street West, Room 403, Hamilton, Ontario, L8S 1C7, Canada. ${ }^{4}$ Department of Medicine, University of Toronto, Toronto, Ontario, Canada. ${ }^{5}$ Dalla Lana School of Public Health, University of Toronto, 155 College Street, Health Science Building, 6th floor, Toronto, Ontario, M5T 3M7, Canada. ${ }^{6}$ Centre for Addiction and Mental Health, Toronto, Ontario, Canada. ${ }^{7}$ School of Rural and Northern Health, Laurentian University, 935 Ramsey Lake Road, Sudbury, Ontario, P3E 2C6, Canada. ${ }^{8}$ Canadian Working Group on HIV and Rehabilitation, 1240 Bay Street, Suite 600, Toronto, Ontario, M5R 2A7, Canada. ${ }^{9}$ Division of Health Care and Outcomes Research and Arthritis and Community Research and Evaluation Unit, Toronto Western Research Institute, 399 Bathurst Street - MP11-322, Toronto, Ontario, M5T 2S8, Canada.

\section{Authors' contributions}

$\mathrm{KO}$ developed the research question, study design, performed the search strategy, reviewed instruments for inclusion, performed the document 
analysis, interpreted findings, and drafted the manuscript. This research was completed as part of KO's PhD thesis research study. AB and AD (cosupervisors) and CS and NY (committee members) participated in the development of the research question, study design, oversaw the analysis and helped to draft the manuscript. KK participated in the document analysis, interpretation of findings, and helped to draft the manuscript. All authors have read and approved the final manuscript.

\section{Competing interests}

The authors declare that they have no competing interests.

Received: 25 March 2010 Accepted: 19 August 2010

Published: 19 August 2010

\section{References}

1. O'Dell MW, Hubert HB, Lubeck DP, O'Driscoll P: Pre-AIDS physical disability: data from the AIDS Time-Oriented Health Outcome Study. Arch Phys Med Rehabil 1998, 79(10):1200-1205.

2. Rusch M, Nixon S, Schilder A, Braitstein P, Chan K, Hogg RS: Impairments, activity limitations and participation restrictions: prevalence and associations among persons living with HIV/AIDS in British Columbia. Health Qual Life Outcomes 2004, 2:46.

3. Henderson M, Safa F, Easterbrook P, Hotopf M: Fatigue among HIVinfected patients in the era of highly active antiretroviral therapy. HIV Med 2005, 6(5):347-352.

4. Blanch J, Rousaud A, Martinez E, De Lazzari E, Peri JM, Milinkovic A, PerezCuevas JB, Blanco JL, Gatell JM: Impact of lipodystrophy on the quality of life of HIV-1-infected patients. J Acquir Immune Defic Syndr 2002, 31(4):404-407.

5. Alonzo AA, Reynolds NR: Stigma, HIV and AIDS: an exploration and elaboration of a stigma trajectory. Soc Sci Med 1995, 41(3):303-315.

6. Palella FJ Jr, Delaney KM, Moorman AC, Loveless MO, Fuhrer J, Satten GA, Aschman DJ, Holmberg SD: Declining morbidity and mortality among patients with advanced human immunodeficiency virus infection. HIV Outpatient Study Investigators. N Engl J Med 1998, 338(13):853-860.

7. Rusch M, Nixon S, Schilder A, Braitstein P, Chan K, Hogg RS: Prevalence of activity limitation among persons living with HIV/AIDS in British Columbia. Can J Public Health 2004, 95(6):437-440.

8. Gaidhane AM, Syed Zahiruddin Q, Waghmare L, Zodpey S, Goyal RC, Johrapurkar SR: Assessing self-care component of activities and participation domain of the international classification of functioning, disability and health (ICF) among people living with HIV/AIDS. AIDS Care 2008, 1-7.

9. Willard S, Holzemer WL, Wantland DJ, Cuca YP, Kirksey KM, Portillo CJ, Corless IB, Rivero-Mendez M, Rosa ME, Nicholas PK, et al: Does "asymptomatic" mean without symptoms for those living with HIV infection? AIDS Care 2009, 21(3):322-328.

10. Kiser AK, Pronovost PJ: Management of Diseases Without Current Treatment Options Something Can Be Done. JAMA 2009, 301(16):1708-1709.

11. Weiss JJ, Osorio G, Ryan E, Marcus SM, Fishbein DA: Prevalence and patient awareness of medical comorbidities in an urban AIDS clinic. AIDS Patient Care STDS 2010, 24(1):39-48.

12. O'Brien KK, Bayoumi AM, Strike C, Young NL, Davis AM: Exploring disability from the perspective of adults living with HIV/AIDS: development of a conceptual framework. Health Qual Life Outcomes 2008, 6:76.

13. O'Brien KK, Davis AM, Strike C, Young NL, Bayoumi AM: Putting episodic disability into context: a qualitative study exploring factors that influence disability experienced by adults living with HIV/AIDS. J Int AIDS Soc 2009, 12(1):5.

14. Hays RD, Shapiro MF: An overview of generic health-related quality of life measures for HIV research. Qual Life Res 1992, 1(2):91-97.

15. Tsasis P: Health-related quality-of-life measurements in HIV/AIDS care. AIDS Patient Care STDS 2000, 14(8):427-438.

16. Clayson DJ, Wild DJ, Quarterman P, Duprat-Lomon I, Kubin M, Coons SJ: A comparative review of health-related quality-of-life measures for use in HIV/AIDS clinical trials. Pharmacoeconomics 2006, 24(8):751-765.

17. Berzon RA, Lenderking WR: Evaluating the outcomes of HIV disease: focus on health status measurement. A Publication for Members of Medical Outcomes Trust. 1998, 3.
18. Cleary PD, Fowler FJ Jr, Weissman J, Massagli MP, Wilson I, Seage GR, Gatsonis C, Epstein A: Health-related quality of life in persons with acquired immune deficiency syndrome. Medical Care 1993, 31(7):569-580.

19. Wilson IB, Cleary PD: Linking clinical variables with health-related quality of life. A conceptual model of patient outcomes. Jama 1995, 273(1):59-65.

20. Finch EP, Brooks D, Stratford P, Mayo N: Physical Rehabilitation Outcome Measures: A Guide to Enhanced Clinical Decision Making. Toronto, Ontario: Canadian Physiotherapy Association 2002

21. McCormick WC, Inui TS, Deyo RA, Wood RW: Long-term care needs of hospitalized persons with AIDS: a prospective cohort study. J Gen Intern Med 1991, 6(1):27-34

22. O'Dell MW, Crawford A, Bohi ES, Bonner FJ Jr: Disability in persons hospitalized with AIDS. Am J Phys Med Rehabil 1991, 70(2):91-95.

23. O'Dell MW, Lubeck DP, O'Driscoll P, Matsuno S: Validity of the Karnofsky Performance Status in an HIV-infected sample. J Acquir Immune Defic Syndr Hum Retrovirol 1995, 10(3):350-357.

24. Manning PK, Cullum-Swan B: Narrative, content, and semiotic analysis. In Handbook of Qualitative Research. Edited by: Denzin NK, Lincoln YS. Thousand Oaks, California: Sage Publications Inc; 1994:.

25. De Boer JB, Sprangers MAG, Arronson NK, Lange JM, van Dam FS: The feasibility, reliability, and validity of the EORTC QLQ-C30 in assessing the quality of life of patients with symptomatic HIV infection or AIDS. Psychology \& Health 1994, 9:65-77.

26. Bucciardini R, Murri R, Guarinieri M, Starace F, Martini M, Vatrella A, Cafaro L, Fantoni M, Grisetti R, Monforte A, et al: ISSQoL: a new questionnaire for evaluating the quality of life of people living with HIV in the HAART era. Qual Life Res 2006, 15(3):377-390.

27. Nokes KM, Wheeler K, Kendrew J: Development of an HIV assessment tool. Image J Nurs Sch 1994, 26(2):133-138.

28. Fanning NM, Emmott S: Evaluation of a quality of life instrument of HIV/ AIDS. AIDS Patient Care 1993, 7(3):161-162.

29. Cella DF, McCain NL, Peterman AH, Mo F, Wolen D: Development and validation of the Functional Assessment of Human Immunodeficiency Virus Infection (FAHI) quality of life instrument. Qual Life Res 1996, 5(4):450-463.

30. Schag CA, Ganz PA, Kahn B, Petersen L: Assessing the needs and quality of life of patients with HIV infection: development of the HIV Overview of Problems-Evaluation System (HOPES). Qual Life Res 1992, 1(6):397-413.

31. Holmes WC, Shea JA: A new HIV/AIDS-targeted quality of life (HAT-QoL) instrument: development, reliability, and validity. Med Care 1998, 36(2):138-154

32. Leplege A, Rude N, Ecosse E, Ceinos R, Dohin E, Pouchot J: Measuring quality of life from the point of view of HIV-positive subjects: the HIVQL31. Qual Life Res 1997, 6(6):585-594.

33. Avis NE: Development of the MQoL-HIV: the multi-dimensional quality of life questionnaire with HIV/AIDS. Quality of Life Newsletter 1997, 17:3-4.

34. O'Connell K, Skevington S, Saxena S: Preliminary development of the World Health Organsiation's Quality of Life HIV instrument (WHOQOLHIV): analysis of the pilot version. Soc Sci Med 2003, 57(7):1259-1275.

35. Pakenham Kl, Rinaldis M: Development of the HIV/AIDS Stress Scale. Psychology \& Health 2002, 17(2):203-219.

36. Nixon S, Cott C: Shifting perspectives: reconceptualizing HIV disease within a rehabilitation framework. Physiotherapy Canada. Physiotherapy Canada 2000, 52:189-207

37. Namisango E, Katabira E, Karamagi C, Baguma P: Validation of the Missoula-Vitas Quality-of-Life Index among patients with advanced AIDS in urban Kampala, Uganda. J Pain Symptom Manage 2007, 33(2):189-202.

38. Robertson KR, Parsons TD, Rogers SA, Braaten AJ, Robertson WT, Wilson S, Hall CD: Assessing health-related quality of life in NeuroAIDS: some psychometric properties of the Neurological Quality of Life Questionnaire (NeuroQOL). J Clin Neurosci 2007, 14(5):416-423.

39. Murdaugh C, Moneyham L, Jackson K, Phillips K, Tavakoli A: Predictors of quality of life in HIV-infected rural women: psychometric test of the chronic illness quality of life ladder. Qual Life Res 2006, 15(5):777-789.

40. Lee D, Patel P, Sachs J, Basinger S, Mathews WC, Barber RE: Psychometric properties of a lipodystrophy scale. AIDS Patient Care STDS 2006, 20(1):30-35.

41. Martinez SM, Kemper CA, Diamond C, Wagner G: Body image in patients with HIV/AIDS: assessment of a new psychometric measure and its medical correlates. AIDS Patient Care STDS 2005, 19(3):150-156. 
42. Guaraldi G, Orlando G, Murri R, Vandelli M, De Paola M, Beghetto B, Nardini G, Ciaffi S, Vichi F, Esposito, et al: Quality of life and body image in the assessment of psychological impact of lipodystrophy: validation of the Italian version of assessment of body change and distress questionnaire. Qual Life Res 2006, 15(1):173-178.

43. Mertz HR, Beck CK, Dixon W, Esquivel MA, Hays RD, Shapiro MF: Validation of a new measure of diarrhea. Dig Dis Sci 1995, 40(9):1873-1882.

44. Barroso J, Lynn MR: Psychometric properties of the HIV-Related Fatigue Scale. J Assoc Nurses AIDS Care 2002, 13(1):66-75.

45. Lubeck DP, Fries JF: Assessment of quality of life in early stage HIVinfected persons: data from the AIDS Time-oriented Health Outcome Study (ATHOS). Qual Life Res 1997, 6(6):494-506.

46. Peterman AH, Cella D, Mo F, McCain N: Psychometric validation of the revised Functional Assessment of Human Immunodeficiency Virus Infection (FAHI) quality of life instrument. Qual Life Res 1997, 6(6):572-584.

47. Ganz PA, Coscarelli Schag CA, Kahn B, Petersen L, Hirji K: Describing the health-related quality of life impact of HIV infection: findings from a study using the HIV Overview of Problems-Evaluation System (HOPES). Qual Life Res 1993, 2(2):109-119.

48. Holmes WC, Shea JA: Performance of a new, HIV/AIDS-targeted quality of life (HAT-QoL) instrument in asymptomatic seropositive individuals. Qual Life Res 1997, 6(6):561-571.

49. Bozzette SA, Hays RD, Berry SH, Kanouse DE: A Perceived Health Index for use in persons with advanced HIV disease: derivation, reliability, and validity. Med Care 1994, 32(7):716-731.

50. Wu AW, Hays RD, Kelly S, Malitz F, Bozzette SA: Applications of the Medical Outcomes Study health-related quality of life measures in HIV/ AIDS. Qual Life Res 1997, 6(6):531-554.

51. Wu AW, Revicki DA, Jacobson D, Malitz FE: Evidence for reliability, validity and usefulness of the Medical Outcomes Study HIV Health Survey (MOSHIV). Qual Life Res 1997, 6(6):481-493.

52. Fang CT, Hsiung PC, Yu CF, Chen MY, Wang JD: Validation of the World Health Organization quality of life instrument in patients with HIV infection. Qual Life Res 2002, 11(8):753-762.

53. WHOQOL (World Health Organization's Quality of Life Instrument) HIV Group: Initial steps to developing the World Health Organization's Quality of Life Instrument (WHOQOL) module for international assessment in HIV/AIDS. AIDS Care 2003, 15(3):347-357.

54. Lenderking WR, Testa MA, Katzenstein D, Hammer S: Measuring quality of life in early HIV disease: the modular approach. Qual Life Res 1997, 6(6):515-530.

55. Holzemer WL, Gygax Spicer J, Skodol Wilson H, Kemppainen JK, Coleman C: Validation of the quality of life scale: living with HIV. J Adv Nurs 1998, 28(3):622-630.

56. Hays RD, Cunningham WE, Sherbourne CD, Wilson IB, Wu AW, Cleary PD, McCaffrey DF, Fleishman JA, Crystal S, Collins R, et al: Health-related quality of life in patients with human immunodeficiency virus infection in the United States: results from the HIV Cost and Services Utilization Study. Am J Med 2000, 108(9):714-722.

57. AIDS Clinical Trials Group Outcomes Committee: ACTG Quality of Life 601602 Health Survey Manual. 1999.

58. Mayers AM, Khoo ST, Svartberg M: The Existential Loneliness Questionnaire: background, development, and preliminary findings. $J$ Clin Psychol 2002, 58(9):1183-1193.

59. Ross MW, Hunter CE, Condon J, Collins P, Begley K: The Mental Adjustment to HIV scale: measurement and dimensions of response to AIDS/HIV disease. AIDS Care 1994, 6(4):407-411.

60. Thompson SC, Nanni C, Levine A: The stressors and stress of being HIVpositive. AIDS Care 1996, 8(1):5-14.

61. Justice AC, Holmes W, Gifford AL, Rabeneck L, Zackin R, Sinclair G, Weissman S, Neidig J, Marcus C, Chesney M, et al: Development and validation of a self-completed HIV symptom index. J Clin Epidemiol 2001, 54(Suppl 1):S77-90.

62. Holzemer WL, Henry SB, Nokes KM, Corless IB, Brown MA, Powell-Cope GM, Turner JG, Inouye J: Validation of the Sign and Symptom Check-List for Persons with HIV Disease (SSC-HIV). J Adv Nurs 1999, 30(5):1041-1049.

63. Burgess AP, Irving G, Riccio M: The reliability and validity of a symptom checklist for use in HIV infection: a preliminary analysis. Int J STD AIDS 1993, 4(6):333-338
64. Holzemer WL, Hudson A, Kirksey KM, Hamilton MJ, Bakken S: The revised Sign and Symptom Check-List for HIV (SSC-HIVrev). J Assoc Nurses AIDS Care 2001, 12(5):60-70.

65. Whalen CC, Antani M, Carey J, Landefeld CS: An index of symptoms for infection with human immunodeficiency virus: reliability and validity. $J$ Clin Epidemiol 1994, 47(5):537-546.

66. Lopez OL, Wess J, Sanchez J, Dew MA, Becker JT: Neurobehavioral correlates of perceived mental and motor slowness in HIV infection and AIDS. J Neuropsychiatry Clin Neurosci 1998, 10(3):343-350.

67. Wagner GJ, Rabkin JG: Development of the Impact of Weight Loss Scale (IWLS): a psychometric study in a sample of men with HIV/AIDS. AIDS Care 1999, 11(4):453-457.

doi:10.1186/1477-7525-8-88

Cite this article as: O'Brien et al:: How do existing HIV-specific instruments measure up? Evaluating the ability of instruments to describe disability experienced by adults living with HIV. Health and Quality of Life Outcomes 2010 8:88.

\section{Submit your next manuscript to BioMed Central and take full advantage of:}

- Convenient online submission

- Thorough peer review

- No space constraints or color figure charges

- Immediate publication on acceptance

- Inclusion in PubMed, CAS, Scopus and Google Scholar

- Research which is freely available for redistribution

Submit your manuscript at www.biomedcentral.com/submit
C Biomed Central 